\title{
An experimental study of intraspecific competition within several forage crops (1).
}

\author{
Luisa ZANNONE, Louis ASSEMAT (*), Pietro ROTILI, Pierre JACQUARD (*) \\ Istituto Sperimentale per le Colture Foraggere, 25 Viale Piacenza, I 20075 Lodi (Italia). \\ (*) CNRS, Centre Louis-Emberger, BP 5051, F 34033 Montpellier Cedex
}

Additional key-words : Cocksfoot, tall fescue, lucerne, red clower, association effect, density effect, homogeneity, dry weight.

Des mélanges binaires ou complexes entre populations d'une même espèce (dactyle, fétuque élevée, luzerne, trèfle violet) ont été réalisés en Italie, à Lodi ou à Rome. La synthèse des résultats expérimentaux accumulés montre l'importance de la relation entre homogénéité et rendement pour expliquer les performances et le devenir d'une association. L'intérêt agronomique d'associations intra-spécifiques semble douteux : c'est la structure interne du peuplement qu'il faut travailler dans le sens d'une plus grande homogénéité.

Les effets de l'association se manifestent toujours par des relations de compétition, au niveau des populations et au niveau de la plante individuelle. Les écarts à cette loi générale sont discutés.

Mots clés additionnels : Dactyle, fétuque, luzerne, trèfle violet, effet association, effet densité, homogénéité, poids sec.

\section{INTRODUCTION}

In a program of genetic improvement, it seems logical to adopt, as basic methods, the observation and handling of the plants in the conditions under which they are to be used. This is the reason why, since 1967, RoTILI $\&$ ZANNONE have carried out a program of studies on the effects of intraspecific competition in some forage crops (lucerne, red clover, cocksfoot, tall fescue). This program was oriented towards two distinct objectives :

1 - To appreciate the necessity of recognizing the effects of competition among individuals in the design of experiments for the choice of the mother plants and for the

(1) This work has been carried out with financial support from the Centro Nazionale delle Ricerche (CNR) and under the sponsorship of the agreement for collaborative program between CNR and the Centre National de la Recherche Scientifique. progeny tests, when selecting within a species for plant breeding ;

2 - To evaluate the agronomical interest of growing mixed crops of different cultivars.

It is intended here to present a synthesis of the major significant results of these experiments as an answer to the preceding questions.

\section{II. - MATERIAL AND METHODS}

The basic pattern of the described experiments consisted of dense sward conditions with a fixed and constant initial population density :

1 - pure stands ;

2 - binary mixtures (associations of two populations in equal proportions) ; 
TABLE 1

Experimental conditions peculiar to each species

Modalités expérimentales particulières à chaque espèce

\begin{tabular}{|c|c|c|c|c|c|c|}
\hline Species & \multicolumn{2}{|l|}{ Cocksfoot } & Tall fescue & \multicolumn{2}{|l|}{ Lucerne } & Red clover \\
\hline Site & \multicolumn{2}{|l|}{ Rome } & Lodi & \multicolumn{2}{|l|}{ Lodi } & Rome \\
\hline Experimental environment & \multicolumn{2}{|l|}{ Greenhouse } & Field & \multicolumn{2}{|l|}{ Field } & Greenhouse \\
\hline Experimental unit & \multicolumn{2}{|l|}{ Box } & Plot & \multicolumn{2}{|l|}{ Plot } & Box \\
\hline$(\mathrm{L} \times \mathrm{l}) \times \mathrm{d} \mathrm{cm}$ & \multicolumn{2}{|c|}{$(39 \times 18) \times 50$} & $56 \times 25$ & \multicolumn{2}{|l|}{$99 \times 20$} & $(39 \times 18) \times 50$ \\
\hline Number of individuals/unit & \multicolumn{2}{|l|}{26} & 14 & \multicolumn{2}{|l|}{69} & 26 \\
\hline $\begin{array}{l}\text { Width between individuals } \\
\text { in the row }(\mathrm{cm})\end{array}$ & \multicolumn{2}{|l|}{1.5} & 4.0 & \multicolumn{2}{|l|}{1.4} & 1.5 \\
\hline Number of rows & \multicolumn{2}{|l|}{2} & 1 & \multicolumn{2}{|l|}{1} & 2 \\
\hline $\begin{array}{l}\text { Mean available area/individual } \\
\left(\mathrm{cm}^{2}\right)\end{array}$ & \multicolumn{2}{|l|}{27} & 100 & \multicolumn{2}{|l|}{29} & 27 \\
\hline Number of replications & \multicolumn{2}{|l|}{5} & 4 & \multicolumn{2}{|l|}{4} & 5 \\
\hline Tested material and earliness & $\begin{array}{ll}1 & \text { Chantemille } \\
2 & \text { Dora } \\
3 & \text { Dorise } \\
4 & \text { Floreal } \\
5 & \text { Montpellier } \\
6 & \text { Prairial } \\
7 & \text { Prius } \\
8 & \text { Mullus } \\
& \end{array}$ & $\begin{array}{r}\mathrm{LL} \\
\mathrm{E} \\
\mathrm{L} / 2 \\
\mathrm{E} \\
\mathrm{VE} \\
\mathrm{I} \\
\mathrm{E} \\
\mathrm{E} / 2\end{array}$ & $\begin{array}{l}8 \text { clones from } \\
\text { a natural } \\
\text { population } \\
\text { collected } \\
\text { near Lodi }\end{array}$ & $\begin{array}{l}1 \text { cv Florida } \\
2 \text { Family N } \\
3 \text { Family P } \\
4 \text { Family Q } \\
5 \text { Family } 1558\end{array}$ & $\begin{array}{l}\mathrm{E} \\
\mathrm{L} \\
\mathrm{L} \\
\mathrm{L} \\
\mathrm{E}\end{array}$ & $\begin{array}{l}1 \text { Natural population } \\
2 \text { Mass selection } \\
3 \text { Natural population } \\
4 \text { Longevo } \\
5 \text { Spadone d'Ivrea } \\
6 \text { Red Head } \\
7 \text { Celtic } \\
\text { (1) (2) }\end{array}$ \\
\hline Number of cuttings & $5+3$ & & $6+2$ & $5+5$ & & 3 \\
\hline
\end{tabular}

(1) VE : Very early; E : early ; E/2 : Medium-early ; L/2 : Medium-late ; L : Late ; LL : Very late.

(2) Red clover : 6 and 7 are tetraploid; 1 and 3 are respectively from Roma and Latina

3 - complex mixtures (associations of $\mathrm{k}$ populations in equal proportions).

The experimental design, for each species, is summarized in table 1. Previous publications must be consulted for more details (see also Appendix I) :

1) lucerne Medicago sativa L. (RoTILI \& ZANNONE, 1975 ; Rotili et al., 1976 ; ASSEMAT, 1977 ; RoTILI, 1979) ;

2) red clover Trifolium pratense L. (ROTILI et al., 1977 ; JACQUARD et al., 1978) ;

3) cocksfoot Dactylis glomerata L. (ROTILI \& ZANNONE, 1977) ;

4) tall fescue Festuca arundinacea Schrb. (Rotili et al., 1977).

The measurements were made at the time of cutting and, except for cocksfoot usually plant by plant. Estimation of dry weight was sometimes carried out simultaneously, in the experiments with legumes, with measurements of height, and census recording of the number of stems or inflorescences per individual.

The biometrical analyses were mainly centred on binary mixtures, which were laid out in complete diallel (all possible combinations of the several populations included) and principally concerned with the harvested biomass, the optimization of which is the economic objective for the studied forage crop.

\section{III. - EFFECTS OF COMPETITION AT THE COMMUNITY LEVEL}

\section{A. Analysis of binary associations}

The analysis is performed on the harvested biomass (dry weight) of the association and on the difference (domination) between the two partners, in binary mixtures, and of the pure stand. Taking into account the similar experimental accuracy (table 2) for pure stands and mixtures, an additive model can be accepted as well adapted for the majority of cases.

In this model, codification of data is :

$Y_{i / j}=$ measurement on $i$ in the presence of $j$ in a binary association $(\mathrm{i}, \mathrm{j})$

$Y_{i / i}=$ measurement on $i$ in the presence of $i$ (in pure stand) 
TABLE 2

Coefficient of variation $\left(\frac{S_{e}}{x} \times 100\right)$ for the analysis of variance of pure stands and binary mixtures

Coefficient de variation $\left(\frac{S_{e}}{x} \times 100\right)$ pour l'analyse de la variance des cultures pures et des mélanges binaires

(dry weight/experimental unit)

\begin{tabular}{lcc}
\hline & Pure stands & Binary mixtures \\
\hline Cocksfoot & 10.5 & 11.5 \\
\hline Tall fescue & 20.4 & 17.6 \\
\hline Lucerne & 14.5 & 15.1 \\
\hline Red clover & 10.6 & 10.3 \\
\hline & $\begin{array}{l}\mathrm{x}=\text { general mean } \\
\mathrm{S}_{\mathrm{e}}=\text { residual error }\end{array}$ \\
\hline
\end{tabular}

and the definitions of the parameters are:

General Associating Ability (GAA) : mean performance of the associations containing a population.

General Dominating Ability (GDA) : mean degree of domination of a population.

Specific Associating Ability (SAA) : ability of two populations to give a performance, in association, differing from that expected from the additivity of their respective GAA.
Specific Dominating Ability (SDA) : specific degree of domination particular to the association of two populations.

General Associating Ability corrected by the performance in pure stand : GAA after correction for the differences between pure stands, a parameter allowing the study of what is due to association.

General Dominating Ability corrected by the pure stand : GDA after correction, expressing the domination due to association.

Already published data for dry matter yield showed that the mean effects of GAA and GDA are highly significant $(P=0.01)$ for all cuttings and species, while the interaction effects (SAA and SDA) are almost always nonsignificant. This is also valid for plant height and number of stems, in lucerne as well as in red clover (table 3).

A conclusion of this analysis is that the performance of the mixtures is a property of the associated populations :

$Y_{i / j}+Y_{j / i}=$ general mean of the associations + GAA $_{i}$ $+\mathrm{GAA}_{\mathrm{j}}$

$Y_{i / j}-Y_{j / i}=G D A_{i}-G D A$

For whatever characteristic (dry matter weight, plant height or number of stems) the greatest importance must be assigned to the GDA mean effects. This is a consequence of general competition situations at the level of the plastic response of the constituents of the mixtures $(+-)$.

The associations which perform best are those between populations showing the best GAA. On the other side, poorly performing associations are derived from either low GAA populations or from the combination of a high GAA with a low GAA population.

Beside GAA and GDA for a given characteristic, other components of vigour also have to be considered in the interpretation of the response of populations when grown

TABLE 3

Statistical significance ( $F$ test) of the diallel analysis parameters for plant height and stem number in lucerne and red clover

Signification statistique (test $F$ ) des paramètres de l'analyse diallele pour la hauteur des plantes et le nombre de tiges chez la luzerne et le trèfle violet

\begin{tabular}{|c|c|c|c|c|c|c|c|c|}
\hline \multirow[b]{2}{*}{ Rank of cuttings } & \multicolumn{4}{|c|}{ Plant height } & \multicolumn{4}{|c|}{ Stems number/plant } \\
\hline & 1 & 2 & 3 & 4 & 1 & 2 & 3 & 4 \\
\hline \multicolumn{9}{|l|}{ Lucerne } \\
\hline \multicolumn{9}{|l|}{ density : $29 \mathrm{~cm}^{2} / 1 \mathrm{pl}$} \\
\hline $\begin{array}{l}\text { GAA } \\
\text { SAA }\end{array}$ & $65.2^{* * * *}$ & $39.3^{* * * *}$ & $23.3^{* * * *}$ & $68.1^{* * * *}$ & $21.6^{* * * *}$ & $16.4^{* * * *}$ & $4.6^{* *}$ & $5.3^{* *}$ \\
\hline GDA & $90.9^{* * * *}$ & $37.4^{* * * *}$ & $35 . \overline{3}^{* * * *}$ & $91.9^{* * * *}$ & $25.2 * * * *$ & $16 . \overline{7} * * * *$ & $8 . \overline{2 * * *}$ & $7 . \overline{3^{* * *}}$ \\
\hline SDA & 1.2 & - & - & - & - & 1.7 & 1.4 & - \\
\hline \multicolumn{9}{|l|}{ density : $100 \mathrm{~cm}^{2} / 1 \mathrm{pl}$} \\
\hline GAA & $236.0^{* * * * *}$ & $64.4^{* * * *}$ & $32.5 * * * *$ & $24.8^{* * * *}$ & $75.0^{* * * *}$ & $40.0^{* * * *}$ & $11.4^{* * * * *}$ & $4.7^{* * *}$ \\
\hline SAA & 2.2 & 2.1 & 1.1 & 1.0 & 1.1 & 1.0 & - & - \\
\hline GDA & $524.4^{* * * *}$ & $236.0^{* * * * *}$ & $81.5^{* * * *}$ & $58.5^{* * * * *}$ & $119.7^{* * * * *}$ & $113.0^{* * * * *}$ & $81.9^{* * * *}$ & $61.4^{* * * *}$ \\
\hline SDA & - & 1.1 & 1.0 & - & - & 1.3 & - & 1.4 \\
\hline \multicolumn{9}{|l|}{ Red clover } \\
\hline \multicolumn{9}{|l|}{ density : $27 \mathrm{~cm}^{2} / 1 \mathrm{pl}$} \\
\hline GAA & $116.1^{* * * *}$ & $75.1^{* * * *}$ & $36.0^{* * * *}$ & & $16.0^{* * * *}$ & $5.7^{* * * *}$ & $6.3^{* * * *}$ & \\
\hline SAA & - & - & - & & 1.1 & - & - & \\
\hline GDA & $102.1 * * * *$ & $160.4^{* * * *}$ & $142.5^{* * * *}$ & & $21.1^{* * * *}$ & $79.0^{* * * *}$ & $44.2^{* * * *}$ & \\
\hline SDA & 1.6 & 1.6 & - & & & 1.3 & - & \\
\hline
\end{tabular}


in mixtures : earliness of flowering, rate of growth and rate of regrowth.

\section{B. Binary associations and pure stands}

The agronomic interest of an association has to be considered on the basis of its advantage over the performance of the best population in a pure stand, or, at least, of its best partner in a pure stand. Previously published data for lucerne, red clover, fescue and cocksfoot showed that no association outyielded the best performing pure stand of the experiment. The only exception was in cocksfoot, when 4 out of the 7 associations had greater yields than the best performing pure stand. This advantage was seen only in three harvests out of eight and was never greater than $5 \%$.

Cocksfoot was the only species among the 4 studied in which situations of "cooperation" appeared through the course of the harvests. These situations generally occurred during the transition from competition in favour of one component to competition in favour of the other.

Except for these cases, either for cocksfoot or for the other species, the advantage of an association over its best pure stand generally results from competition, with over compensation favouring one component.

\section{Use of pure stands for the prediction of the response in binary association}

The test of the GAA corrected for the performance in pure stand ( $\mathrm{g}$ ' parameter in Gallais, 1970) allows, if signi- ficant, rejection of the hypothesis of a positive relationship between the performance in pure stand and the GAA. This test was never significant for the whole series of harvests in the experiments except in 2 cuttings of cocksfoot (harvests 3 and $8,0.01<P<0.05$ ). In the majority of situations, a strict correlation exists between the performance in pure stand and the GAA (table 4) ; the minimal significant values of $R^{2}$ are in fact 0.68 and 0.61 , corresponding to the third and eight harvests of cocksfoot, respectively.

Conversely, the GDA corrected with the pure stands (c' parameter in GaLlaIS, 1970) are highly significant $(P<0.01)$, excepted for some harvests of tall fescue.

The results obtained from the pure stands allow one to estimate the $G A A$ of the populations and to predict the mean performance of the associations with considerable accuracy. However the domination of one population over another in the association experiments is generally not predictable from the results from the pure stands.

A more detailed examination of the domination has shown that :

1) On tall fescue, the uncontrolled factors of the environment (measured as residual variances) had a greater impact on production than the controlled factors (nature of the partner population). In associations of this species, any random advantage for one of the constituents of the association did not result in a disadvantage for the other component (table 5). This relative independence among components could be explained by the larger space available for the growth of the individual (table 1).

2) A proportionality relationship exists between the relative domination and the ratio of population vigour : vigour

TABLE 4

Linear correlation between the harvested biomass in pure stands and the GAA (not corrected for the performance in pure stand) Corrélation linéaire entre la biomasse récoltée en culture pure et l'AGA (non corrigée pour les performances en culture pure)

\begin{tabular}{|c|c|c|c|c|c|c|c|c|c|c|}
\hline $\begin{array}{l}\text { Rank of } \\
\text { the cuttings }\end{array}$ & 1 & 2 & 3 & 4 & 5 & 6 & 7 & 8 & 9 & 10 \\
\hline Tall fescue & $0.93^{++}$ & $0.97^{++}$ & $0.96^{++}$ & $0.93^{++}$ & $0.97^{++}$ & $0.98^{++}$ & $0.98++$ & $0.99^{++}$ & & \\
\hline Lucerne & $1.00^{++}$ & $0.93^{++}$ & $0.99^{+}$ & $0.94^{++}$ & $0,98^{++}$ & $0.99^{++}$ & 0.76 & 0.62 & 0.86 & 0.7 \\
\hline
\end{tabular}

TABLE 5

Ratio of the residual variance of the analysis on the differences between the two components of the associations $\left(y_{i / j}-y_{j / i}\right)$ to the residual variance of the analysis on the performance of the associations $\left(y_{i / j}+y_{j / i}\right)$.

Rapport de la variance résiduelle de l'analyse sur les différences entre les deux composants des associations $\left(y_{i / j}-y_{j / i}\right)$ à la variance résiduelle de l'analyse sur les performances des associations $\left(y_{i / j}+y_{i / i}\right)$.

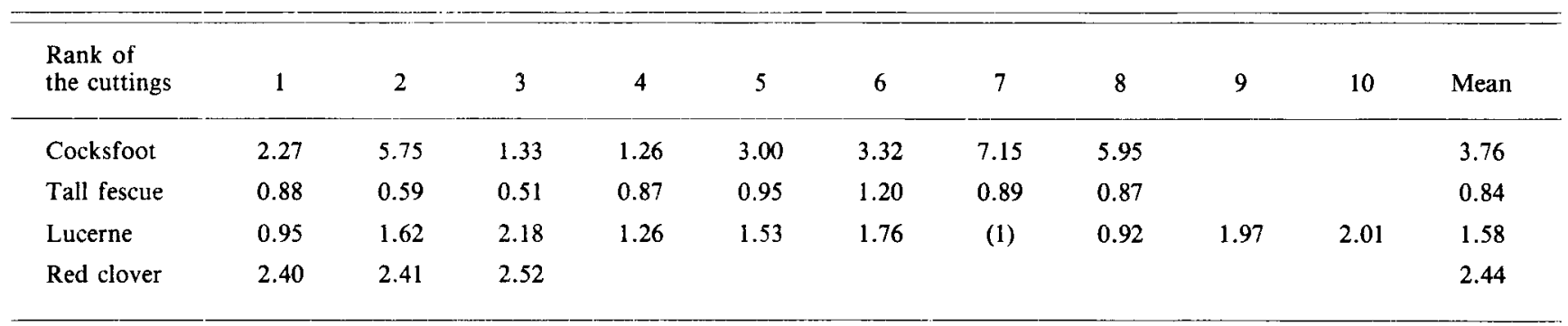

(1) Harvest performed on each plot and not plant by plant. 
measured in pure stand (fig. 1). The degree of proportionality appears to be dependent upon the species and/or the experimental conditions.

When the relationships are examined at the level of the recurrent population for each set of associations that share a common partner (table 6), the model generally fits well for biomass, except when the recurrent population exhibits traits which are very different from the traits of the other populations as, for example, in cocksfoot "Chantemille $n^{\circ} 1$ ", which is very late. The relationship is consistent for other traits in lucerne, but not in red clover.

\section{Analysis of complex mixtures}

The complex mixtures (associations between more than two components) show an increase of the mean differences between the component populations (fig. 2) when compared with binary mixtures.

For 3 species ( 20 populations and 64 associations overall) the ranking of populations is not significantly modifield, indicating that a similar "mechanism" is probably acting both in the binary and in the complex mixtures. In lucerne, a still better agreement between the ranking in binary and complexe mixture is obtained when the biomass (dry weight) is weighted by the number of inflorescen-


Figure 1

Mean relationships between the relative domination $\left(y_{i / j} / y_{j / i}\right)$ and the ratio of vigour in pure stand $\left(y_{i / i} / y_{j / j}\right)$ with $y_{i / i}<y_{i / r}$

Relation moyenne entre domination relative $\left(y_{i / j} / y_{i / i}\right)$ et le rapport de la vigueur en culture pure $\left(y_{i / i} / y_{j / j}\right)$ avec $\left.y_{i / i}<y_{j / j}\right)$.

TABLE 6

Linear correlation between the relative domination $\left(y_{i / j} / y_{j / i}\right)$ and the ratio of the value in pure stand $\left(y_{i / i} / y_{j / i}\right)$ for each population (cf. Appendix I for more details).

Corrélation linéaire entre la domination relative $\left(y_{i / j} / y_{j / i}\right)$ et le rapport des valeurs en culture pure $\left(y_{i / i} / y_{i / j}\right)$ pour chaque population (cf. Annexe I pour plus de détails).

\begin{tabular}{|c|c|c|c|c|c|}
\hline $\begin{array}{l}\text { Tested material } \\
\text { (cf. table 1) }\end{array}$ & & Dry weight & Height/plant & $\mathrm{Stem} / \mathrm{pl}$ & Stem/experimental unit \\
\hline \multicolumn{6}{|l|}{ Lucerne (Lodi) } \\
\hline \multirow[t]{2}{*}{$\mathrm{n}=4$} & 1 & $0.985^{* * *}$ & $0.998^{* * *}$ & $0.967^{* * *}$ & \\
\hline & 2 & $0.975^{* * *}$ & $0.991^{* * *}$ & $0.963^{* * *}$ & \\
\hline \multirow[t]{3}{*}{$\mathrm{df}=\mathbf{2}$} & 3 & $0.977^{* * *}$ & $0.979^{* * *}$ & $0.980^{* * *}$ & \\
\hline & 4 & $0.907^{* *}$ & $0.985^{* * *}$ & $0.966^{* * *}$ & \\
\hline & 5 & $0.944^{* *}$ & $0.997^{* * *}$ & $0.963^{* * *}$ & \\
\hline \multirow[t]{2}{*}{ Red clover (Rome) } & 1 & $0.972^{* * *}$ & $0.920^{* * *}$ & 0.843 & 0.534 \\
\hline & 2 & $0.989^{* * *}$ & 0.651 & 0.506 & 0.072 \\
\hline \multirow[t]{2}{*}{$\mathrm{n}=6$} & 3 & $0.957^{* * *}$ & 0.739 & 0.687 & 0.463 \\
\hline & 4 & $0.986^{* * *}$ & 0.682 & 0.333 & 0.113 \\
\hline \multirow[t]{3}{*}{$\mathrm{df}=4$} & 5 & $0.857^{*}$ & 0.622 & 0.692 & 0.376 \\
\hline & 6 & $0.974^{* * *}$ & $0.958^{* * *}$ & 0.766 & 0.481 \\
\hline & 7 & $0.990^{* * *}$ & 0.771 & 0.792 & 0.264 \\
\hline \multirow[t]{2}{*}{ Cocksfoot } & 1 & 0.591 & & & \\
\hline & 2 & $0.756^{*}$ & & & \\
\hline \multirow[t]{2}{*}{$\mathrm{n}=7$} & 3 & $0.974^{* *}$ & & & \\
\hline & 4 & $0.830^{*}$ & & & \\
\hline \multirow[t]{4}{*}{$\mathrm{df}=5$} & 5 & $0.934^{* *}$ & & & \\
\hline & 6 & $0.774^{*}$ & & & \\
\hline & 7 & $0.890^{* * *}$ & & & \\
\hline & 8 & $0.830^{*}$ & & & \\
\hline \multirow[t]{3}{*}{ Tall fescue } & 1 & $0.954 * * *$ & & & \\
\hline & 2 & $0.770^{*}$ & & & \\
\hline & 3 & $0.907 * * *$ & & & \\
\hline \multirow[t]{2}{*}{$\mathrm{n}=7$} & 4 & $0.909^{* * *}$ & & & \\
\hline & 5 & $0.935^{* * *}$ & & & \\
\hline \multirow{3}{*}{$\mathrm{df}=5$} & 6 & $0.956^{* * *}$ & & & \\
\hline & 7 & $0.888^{* * *}$ & & & \\
\hline & 8 & $0.945^{* * *}$ & & & \\
\hline
\end{tabular}



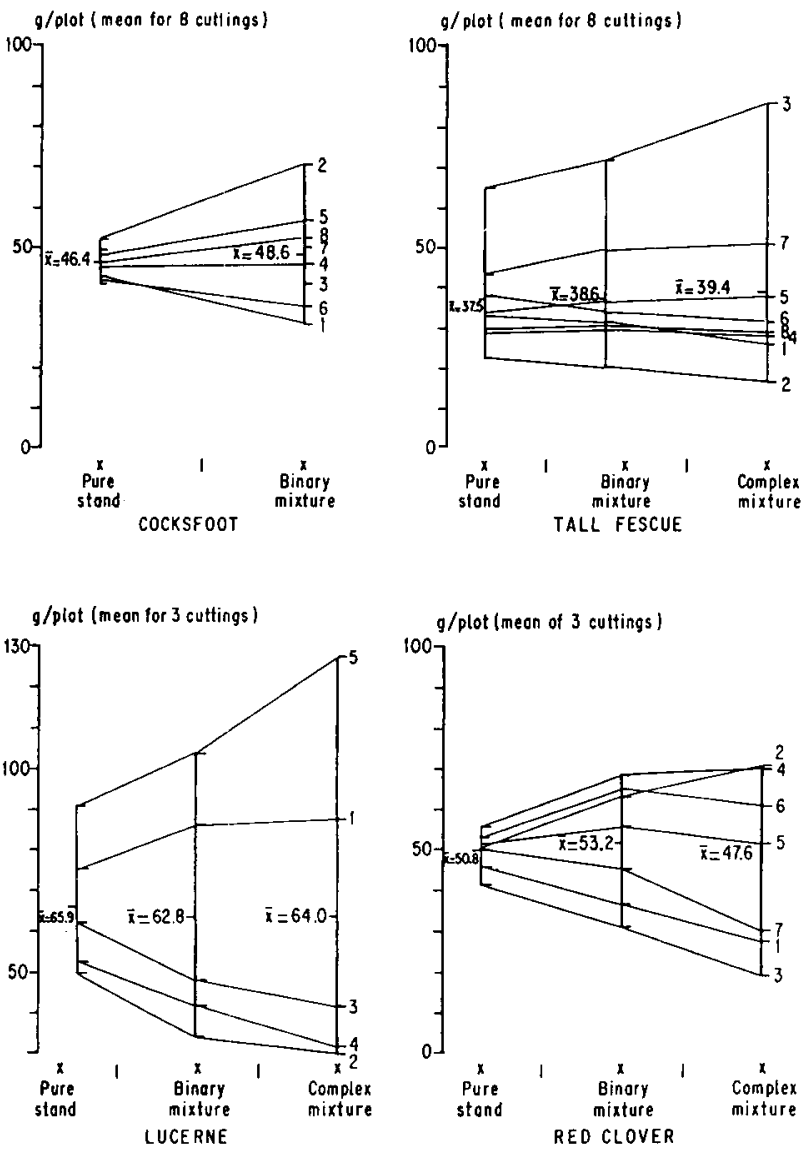

Figure 2

Mean ranking of the populations in pure stands, in binary mixtures and in complex mixtures.

Classement moyen des populations en culture pure, mélange binaire et mélange complexe.

ces/plant (RoTILI, 1975), as a composite index. The mean of the complex mixture is very close to the mean of the binary associations. In the set of experiments described, the mixtures with more than 2 components do not show an agronomical advantage, and plant breeders would have difficulty in working with these more complex mixtures, despite their interest for an efficient phenotypic selection at the family level. This is because of technical limitations in lay-out and in the collection of data. The prediction of the yield of such mixtures from the pure stands is beyond the scope of this study. The use of complex mixtures of species for the experimental study of the dynamics of multispecies communities is developed elsewhere (JACQUARD et al., 1983).

\section{IV. - EFFECTS OF COMPETITION AT THE LEVEL OF THE INDIVIDUAL}

Analysis at the level of the experimental unit does not take into account variation between individuals. Of course, this plays a part in the perenniality of the populations, which is a characteristic of great importance for the management of temporary grasslands.

The study of frequency distributions is not extremely precise due to the low number of individuals per plot. Nevertheless, taking tall fescue as an example, some trends can be found.

In dense swards, the distribution of the individual dry weights, from the first harvest onward, is skewed to the right. The log-normality increases with time : the dominated individuals cannot make up their delay and are more and more depressed (table 7 : see also ROTILI, 1979, fig. 4 for lucerne, where a cumulative effect is clear). The variability between plants, measured through the coefficient of variation, increases under the influence of reciprocal effects ; but, mortality is very low at the end of the experiment (less than $1.5 \%$ ).

In the experiment with tall fescue, clone 3, which grows more rapidly than the others, shows a contrasting response : the asymmetry which was high at the first cutting, decreases.

TABLE 7

Analysis of the variability of the individuals of tall fescue $=$ mean dry weight $/$ plant $(\mathrm{DW} / \mathrm{pl})$, coefficient of variation (C.V.) and disymmetry (Dim)

Analyse de la variabilité des individus de fétuque élevée = poids sec moyen $/ p l a n t e(D W / p l)$, coefficient de variation (C.V.) et dissymétrie (Diss)

\begin{tabular}{|c|c|c|c|c|c|c|c|c|c|c|}
\hline $\begin{array}{l}\text { Clone } \\
\text { Number }\end{array}$ & & 1 & 2 & 3 & 4 & 5 & 6 & 7 & 8 & Mean \\
\hline \multicolumn{11}{|l|}{ Cutting } \\
\hline \multirow[t]{3}{*}{$-6=-6$} & $\mathrm{DW} / \mathrm{pl}$. & 3.2 & 3.6 & 5.8 & 3.4 & 3.8 & 4.1 & 3.2 & 3.6 & 3.84 \\
\hline & C.V. & 33.7 & 26.7 & 31.5 & 32.8 & 32.3 & 38.2 & 29.6 & 25.9 & 31.33 \\
\hline & DISS. & 0.05 & 0.08 & $0.72 *$ & 0.28 & 0.57 & 0.10 & 0.05 & 0.57 & 0.303 \\
\hline \multirow[t]{2}{*}{2} & C.V. & 40.5 & 47.3 & 38.3 & 46.4 & 36.3 & 30.9 & 31.7 & 41.3 & 39.14 \\
\hline & Diss. & 0.35 & $0.64 *$ & 0.43 & $0.95 *$ & $0.99 *$ & 0.41 & $0.91^{*}$ & 0.14 & 0.602 \\
\hline \multirow{3}{*}{5} & $\mathrm{DW} / \mathrm{pl}$. & 1.2 & 0.4 & 2.6 & 1.4 & 1.1 & 1.2 & 1.3 & 0.8 & 1.25 \\
\hline & C.V. & 52.8 & 78.6 & 50.4 & 44.2 & 57.9 & 42.1 & 72.0 & 78.2 & 59.53 \\
\hline & DISS. & 0.53 & $1.09 *$ & 0.45 & $0.75^{*}$ & $0.63 *$ & 0.29 & $0.91 *$ & $1.00 *$ & 0.706 \\
\hline \multirow[b]{2}{*}{7} & $\mathrm{DW} / \mathrm{pl}$. & 6.0 & 3.0 & 11.2 & 3.8 & 4.4 & 7.5 & 6.5 & 3.8 & 5.77 \\
\hline & C.V. & 62.2 & 52.3 & 54.4 & 64.3 & 65.1 & 47.8 & 78.9 & 68.7 & 61.70 \\
\hline
\end{tabular}


This trend is similar to the tendency described for spaced plants (ROTILI, 1979, fig. 5).

These results can be simply interpreted by the hypothesis that, within a species, the populations (or the genotypes) wich exhibit a low growth potential suffer the most from competition effects between genotypes (or between phenotypes). The populations (or genotypes) with low susceptibility to competition pressure seem to be composed of genotypes (or give phenotypes) which are able to avoid any delay in development (earliness, rate of regrowth) and therefore can escape the cumulative effect of competition (RoTILI, 1979). The experimental results of RoTILI (1979) - fig. 6 for pure stand and figure 7 for association - can be used to deduce this hypothesis.

The association of two populations of contrasting vigour will result in a new mixed population where the coefficient of variation and the asymmetry are increased during the successive harvests, and one population may eventually be eliminated. The mixture of two identical populations will give a well balanced and stable association. An example of associations belonging to each of the two types is presented in figure 3, with CV or coefficient of asymmetry calculated for pure stands and association performances.

This phenomenon of temporal variation in associations has been observed during the progress of other experiments, with fluctuations due to the genotypic heterogeneity of the plant material (see, for lucerne, ROTILI \& ZANNONE, 1971).

\section{V. - INTERPRETATION \\ OF THE COMPETITION PHENOMENA}

When the niche available for a plant decreases, growth is reduced. In lucerne, under fixed experimental conditions, this reduction is proportional to the vigour of the population (measured by the dry weight at relatively low density) and is a measure of the effects of competition between individuals (fig. 4).

In the case of association between two populations, this effect is biased by the competitive nature of the interferences (one of the populations is at an advantage, the other
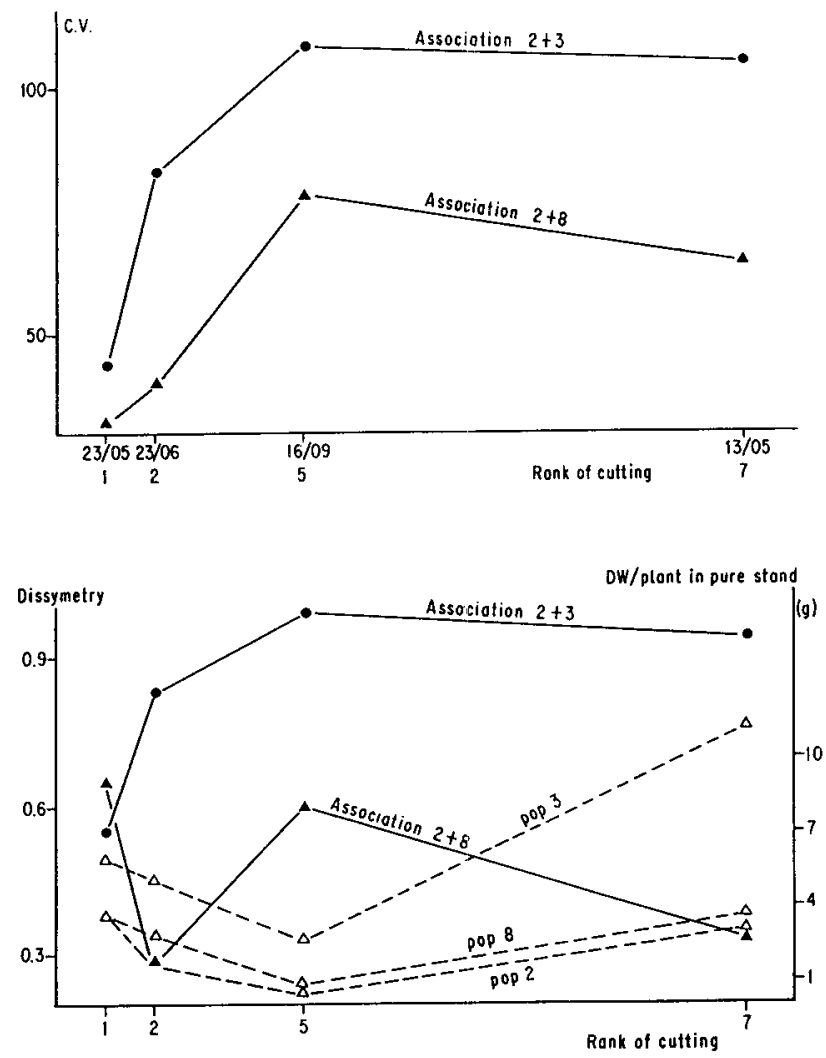

Figure 3

Change with time in the coefficient of variation between individuals and in the disymmetry of the distributions of the individual dry weights and of the dry weight/plant in pure stands $(\Delta)$, for two associations:

one of the "contrasted" type $(2+3)(\bullet)$, the other of the "balanced" type $(2+8)(\Delta)$, for 4 harvests of tall fescue.

Evolution du coefficient de variation entre les individus et de la dissymétrie dans les distributions des poids secs individuels pour deux associations : type " contrasté " $(2+3)(0)$ et type "équilibré $(2+8)$ $(\Delta)$ et du poids sec moyen de leurs constituants en culture pure $(\Delta)$, pour 4 coupes chez la fétuque élevée.

at a disadvantage, as compared to their pure stands). The example of figure 5, in fact, shows that this effect, at the level of one species, is equivalent to a very symmetrical change in numerical density of each population.

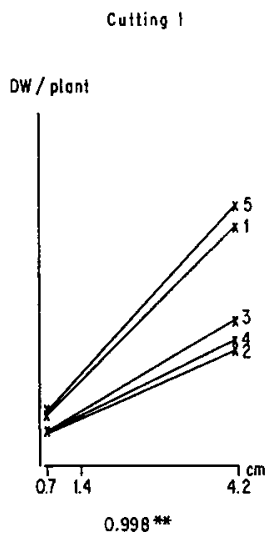

Cutting 2

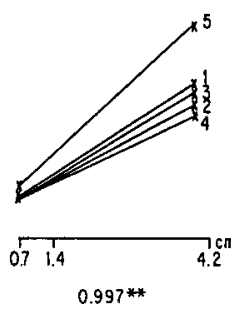

Figure 4

Variation in the dry weight/plant, in lucerne, when the initial distance between plants increases from 0.7 to $4.2 \mathrm{~cm}(1 . \ldots .5=$ population code $)$ $b=$ regression coefficient $D . W . /$ density

$r=b / D . W$. at low density.
Evolution du poids sec par plante, chez la luzerne, quand la distance entre les plantes varie de $0,7 \mathrm{~cm}$ à $4,2 \mathrm{~cm}$. $b=$ coefficient de régression. Matière sèche/densité. $r=b / M . S$. à faible densite. 

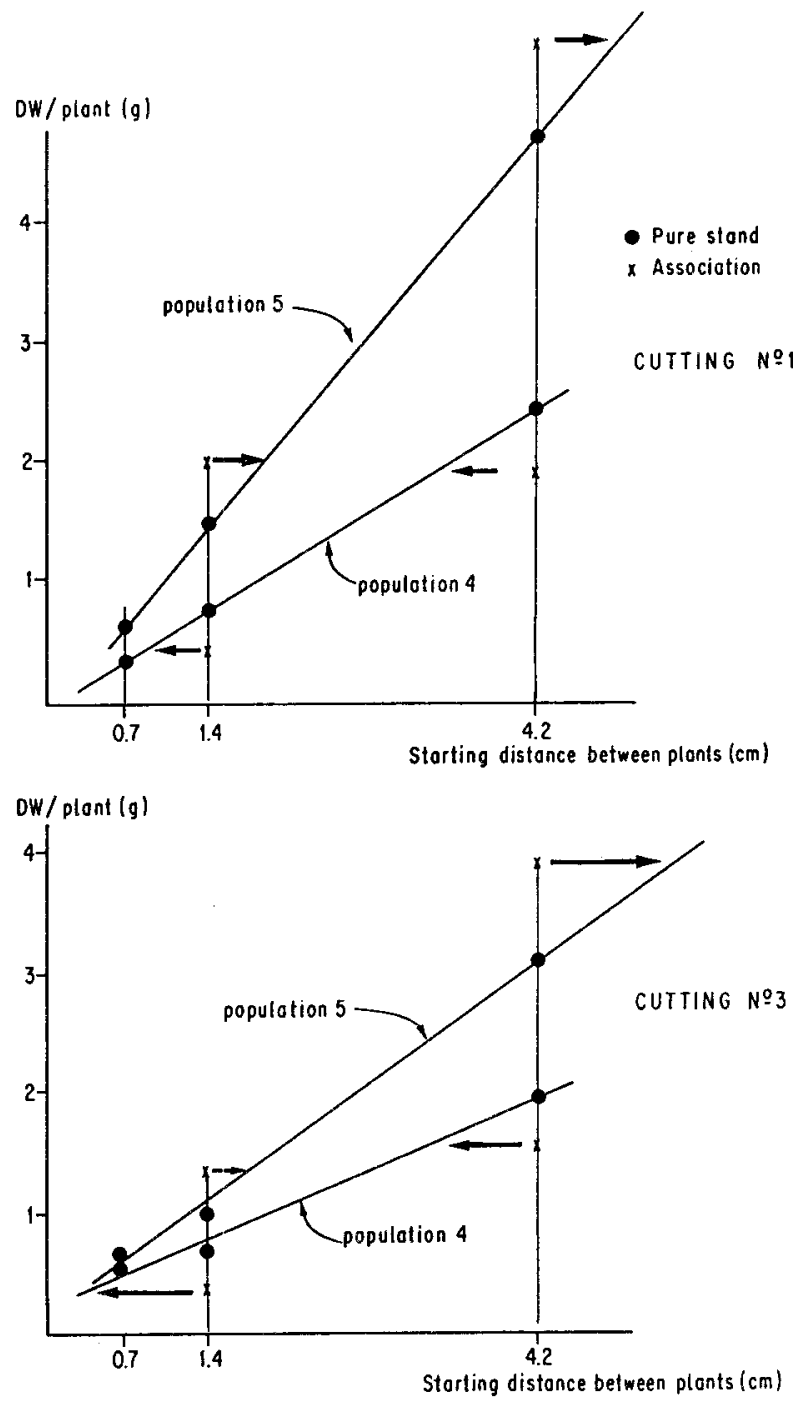

Figure 5

Density effect in lucerne : an example for association $4+5$. Les effets densités chez la luzerne : exemple de l'association $4+5$.

A compensation effect can always be interpreted in terms of variation in density, and this conclusion is easy when the monocultures are performed with several densities as was done in this experiment.

So, it appears that the GAA, defined as the mean effect that minimizes the sum of squares of the deviations between the values observed on the populations, for the different biotic environments and its mean, is only a descriptive parameter. The lack of statistical interactions therefore indicates that the GAA parameter can be used as a good decision criterion for selection of the populations.

The biological phenomenon is therefore mainly reduced to a density effect. Nevertheless, this seems not always true if there are interactions between components and specific direct and associate effects (for example for cocksfoot, in GALlAIS, 1973).

The measurement of this biological density (ROTILI \& ZANNONE, 1970) is a problem which remains open for further investigation.

\section{VI. - CONCLUSION}

At the level of the community, competition (advantage of one component, disadvantage of the other) is common. This result has been well established for intraspecific relationships. (similarly, the data collected at Lodi, on the associations between grasses and legumes, seem to affirm the universality of this phenomenon and this will be confirmed in a further paper). Throughout the growing season there was usually a trade-off in competitive ability of one population over another, for binary mixtures of populations of the same species.

The end result, as averaged over several cuttings during the seasons, was that no population outcompeted another and many times the situations can be described as being mutually cooperative (advantage for each of the 2 populations by reference to their pure stand). The phenomenon of alternate over-compensation, in time, for a species cut several times, occurs in the cocksfoot experiment. Alternatively, the superiority of mixed associations results from agronomical treatments (management alternatively favouring one component at the expense of the other, producing situations of competition with overcompensation).

Two very interesting results are:

1. the existence of a proportionality relationship between the relative domination and the ratio of population vigour ;

2. the fact that when the niche decreases, growth is reduced proportionally to the vigour.

At the population level a positive relationship between homogeneity and production is observed for all the studied species (and mainly for lucerne), except red clover (table 8). For tall fescue, the relationship changes with the harvest time. In lucerne, the numerous experiments conducted by ROTILI and ZANNONE emphasize the intensity of the relation and demonstrate the importance of spatial pattern of the stand (stem density) as a principal component of yield (RoTILI, 1979). However the results of table 8 show the

TABLE 8

Linear correlation between the dry matter production/plot and the coefficient of variation between individuals Corrélation linéaire entre la production de matière sèche/parcelle et le coefficient de variation entre individus

\begin{tabular}{|c|c|c|c|c|c|c|c|}
\hline $\begin{array}{l}\text { Rank of the } \\
\text { cuttings }\end{array}$ & 1 & 2 & 3 & 5 & 6 & 7 & $10^{*}$ \\
\hline Cocksfoot & & 0.18 & & & & & \\
\hline Tall fescue & 0.13 & -0.53 & & -0.56 & & -0.25 & \\
\hline Lucerne & -0.91 & & -0.97 & -0.94 & 0.67 & & -0.95 \\
\hline Red clover & -0.13 & 0.86 & 0.90 & & & & \\
\hline
\end{tabular}

* For some cuttings the measurements have not been taken at the individual level and only at the plot level. 
degree of variation of the relationship between homogeneity of partners and productivity. So, the interest of controlled heterogeneity, as for instance the use of the functional polymorphism, still remain a problem. Some experimental evidence has been published by GALLAIS (1973).

The contradictory results with red clover must be considered with caution. The very wide genetic basis of the populations used could be one of the elements explaining the response. The negative relationship between homogeneity and production results in a mortality of individuals, acting on the more vigorous populations.

The last point, very important for the breeder, is that the association of two constrasting populations (for vigour, rate of regrowth and mainly earlyness, cf. table 1), induces, in all cases and for each of the 4 studied species, an increasing unbalance which results in domination, possibly followed by exclusion of the weaker population. This shows the difficulty in directly applying associations of different populations for agronomical objectives and suggests the possibility of accomplishing such an improvement by the way of a greater homogeneity of pure stands. For lucerne, this was already well demonstrated by RoTILI (1979). Here these conclusions will be generalized to other species and for differents traits, underlining the importance of harvest time (change with time of the plastic response).

However, heterogeneity is interesting for :

1. problems of stability (genotype $\mathrm{x}$ environment interaction) ;

2. production.

Two types of heterogeneity must be distinguished : uncontrolled and controlled ; stable advantages for the association have been obtained for cocksfoot (GALLAIS, 1973).

The advantage of homogeneity cannot be discussed for lucerne; for grasses, the question is more complexe because, heterogeneity is important for the onset of growth, earliness, etc., it can induce an alternate over-compensation. Wich finally results in an advantage of such a dynamics was evident thiefly in interspecific mixtures. This emphasizes the need to analyse competition at different harvest times throughout the experiment.

The suspected importance of experimental effects, as well as detection of differential responses, pinpoints the interest for a follow-up of these studies. Particularly, it would be useful to know to what extent the genotypic heterogeneity of a population explains the wide phenotypic variability induced by a dense sward. Now that certain concepts have been clarified (association ability, competition), estimation of the effects of biological density, which determine the growth in community of plants, will be possible.

Reçu le 22 janvier 1982. Accepté le 24 janvier 1983

\section{ACKNOWLEDGEMENT}

This synthesis has been prepared during a visit to Lodi by L. AsSE MAT with the support of a grant from the Italian Ministry of Foreign Affairs. All authors are indebted to Michael SAWN and Louise JACKSON for the revision of the English.

\section{APPENDIX 1}

Detailed description of the experiments

Cocksfoot (Rotili \& ZANNONE, 1977)

The experiment carried out in Rome included cultivars. 8 pure stands and 28 binary mixtures were grown. Homogeneity in starting populations was obtained by seed grading, sowing in Petri dishes and transplantation of seedlings with well developed roots. The boxes were arranged in a randomized block design.

Tall fescue (Rotili et al., 1977).

32 clones have been studied. The material has been homogenized by growing it in containers for 5 months, after cloning, and then planted in : 1) spaced plant ( 5 plants $\left./ \mathrm{m}^{2}\right)$ with 14 replications; 2 ) in dense sward, with 3 types of growth conditions : pure stand ( 56 plants, all from the same clone), complex mixture of the all 32 clones, binary mixtures from only 8 clones.

Lucerne (RotiLI et al., 1976).

4 So families and 1 cultivar have been studied, grown as pure stand (5), binary mixture (10), and complex mixture of the 5 origins. In summer time, one irrigation was made during the first ten days after each cut. The same amount of water was supplied to each plot. Homogeneity was obtained by : seed calibration, sowing in Petri dishes, transplantation of seedlings.

Red clover (Rotili et al., 1977)

The experiment included 3 early, 1 semi early, and 3 late populations. 7 pure stands 21 binary mixtures and the complex mixture of the 7 populations were grown. Homogeneity in starting of populations was obtained by seed grading, sowing in Petri dishes and transplantation of seedlings with well developed cotyledons. The boxes were arranged in a randomized block design.

\section{REFERENCES}

Assemat L., 1977. Modèles d'analyse de la concurrence entre populations végétales. Thèse Doc. Spécialités Sci. biol., mention Ecol., U.S.T.L., Montpellier, 112 p.

Gallais A., 1970. Modèle pour l'étude des relations d'association binaire. Biométr. Praxim., 11, 51-30.

Gallais A., 1973. Competition and breeding for yield in cocksfoot, in Evaluation of Breeding Material in Herbage Crops, Eucarpia, Rep. Fodder Crops Meeting, Dublin, 4-7 sept. 1972, 201-231.

Jacquard P., Foroughbakhch R., Lumaret R., 1983. Dynamique des relations de compétition entre trois graminées des successions post-culturales, Acta Ecol., EEcol. Gener. (à paraître).

Jacquard P., Rotili P., Zannone L., 1978. Les intéractions génotype $\mathrm{x}$ milieu biologique : analyse diallèle des aptitudes à l'association entre populations de trèfle violet. Ann. Amélior. Plant., 28 (3), 309-325.

Rotili P., 1975. Importanza degli effetti di associazione tra « genotipi » nel miglioramento genetico dell'erba medica. Riv. Agron., 2-3, 348-55.

Rotili P., 1979. Contribution à la mise au point d'une méthode de sélection de la luzerne prenant en compte les effets d'interférence entre les individus. I. Etude expérimentale de la structure de la luzernière. Ann. Amélior. Plant., 29 (4), 353-381.
Rotili P., Zannone L., 1970. Intra- and inter-genotypic competition in Medicago sativa L., Rep. of Eucarpia Fodder Crops Sect. Meeting, Lusignan, 213-236.

Rotili P., Zannone L., 1971. The use of competition in the breeding of lucerne. Quad. Sper. 1st. Forage. Lodi, 3, 41-86.

Rotili P., Zannone L., 1975. Principaux aspects d'une méthode de sélection de la luzerne basée sur des dispositifs qui utilisent la concurrence entre les plantes. Ann. Amélior. Plant., 25 (1), 29-49.

Rotili P., Zannone L., 1977. Analisi degli effetti di associazione in popolazioni di Dactylis glomerata L., Ann. 1st. Sper. Colt. Foraggere, Lodi, 4, 71-82.

Rotili P., Zannone L., 1977. Effetti di associazione e densità in cloni di Festuca (Festuca arundinacea L.). Ann. 1st. Sper. Colt. Foraggere, Lodi, 4, 83-96.

Rotili P., Zannone L., Jacquard P., 1976. Effects of association on the evaluation of lucerne populations. Ann. Amelior. Plant., 26 (2), 139-155.

Rotili P., Zannone L., Jacquard P., 1977. Analisi degli effetti di associazione in popolazioni di Trifoglio violetto (Trifolium pratense L.) Ann. 1st. Sper. Colt. Foraggere, Lodi, 4, 57-69. 